Motrivivência $\quad$ v. 27 , n. 46, p. 84-98, dezembro/2015

\title{
FORMAÇÃO PROFISSIONAL EM EDUCAÇÃO FÍSICA E FISIOTERAPIA: ressonâncias de um projeto de ensino sobre questões socioambientais
}

\author{
Priscila Mari dos Santos \\ Miraíra Noal Manfroi? \\ Cecília Bertuol ${ }^{3}$ \\ Alcyane Marinho ${ }^{4}$
}

\section{RESUMO}

Este estudo apresenta as ressonâncias da participação da comissão organizadora de um projeto de ensino sobre questões socioambientais, desenvolvido em uma universidade pública de Santa Catarina, no contexto de cursos de Educação Física e Fisioterapia. Trata-se de uma pesquisa descritiva com abordagens quantitativa e qualitativa dos dados. Ao final do projeto, 13 participantes responderam a um questionário misto. Os dados foram analisados por meio da estatística descritiva e da técnica de análise de conteúdo. Os resultados indicam, dentre outras questões, que os participantes perceberam contribuições do projeto para aprender mais sobre o tema ambiente e para vislumbrar novas possibilidades para sua atuação profissional. Além disso, perceberam frequentemente a manifestação de competências profissionais.

Palavras-chave: Ensino; Ambiente; Educação Física; Fisioterapia

1 Mestre em Educação Física. UFSC, Florianópolis/Santa Catarina, Brasil. E-mail: priscilamarisantos@hotmail.com

2 Doutoranda em Educação Física. UFSC, Florianópolis/Santa Catarina, Brasil. E-mail: mira_nm@hotmail.com

3 Mestranda em Educação Física. UFSC, Florianópolis/Santa Catarina, Brasil. E-mail: bertuolcecilia@gmail.com

4 Doutora em Educação Física. Professora Adjunta da UDESC, Florianópolis/Santa Catarina, Brasil.

E-mail: alcyane.marinho@hotmail.com 


\section{INTRODUÇÃO}

A temática da formação profissional ganhou destaque a partir da década de 1990, passando por inúmeras transformações. Com a atenção direcionada à Educação Física, a identificação de problemas no contexto da intervenção estimulou o surgimento de inúmeros estudos sobre a formação e a competência profissional na área (FREIRE; VERENGUER; REIS, 2002; MARQUES; FIGUEIREDO, 2014). Podem ser identificadas mudanças na evolução dos elementos que constituem o próprio conceito de formação profissional, especialmente no que se refere à clientela atingida, às entidades que a oferecem e aos conteúdos de aprendizagem (NASCIMENTO, 2002). Na área da Fisioterapia, por sua vez, as alterações estão relacionadas, principalmente, à ruptura da visão que entendia o papel social do fisioterapeuta limitado ao indivíduo doente (REBELLATO; BOTOMÉ, 1999). Os campos de atuação da Fisioterapia aumentaram recentemente (BISPO JÚNIOR, 2009), sendo que as demandas desta área ainda não foram completamente atendidas (MEYER; COSTA; GICO, 2006).

A preparação dos profissionais dessas áreas, principalmente no âmbito da Educação Física, tem sido caracterizada pela diversidade de intervenções de formação no ensino superior que sugerem a ausência de um modelo único ou generalizado, apresentando em sua estrutura a qualificação de um profissional que desempenhe uma demanda de atividades altamente especializadas. Apesar disso, é evidente o reconhecimento social da formação universitária, sendo esse período aquele no qual os indivíduos deveriam ter a possibilidade de ter contato com a base de competências da sua profissão
(NASCIMENTO, 2002; SOUZA; FUCHS; RAMOS, 2014).

A formação inicial universitária tem como uma de suas responsabilidades a aproximação adequada dos alunos à futura realidade de intervenção. Para tanto, as práticas pedagógicas desenvolvidas ao longo do curso são consideradas primordiais (NASCIMENTO et al., 2009), podendo ser inseridas no universo mais amplo das universidades, o qual envolve o ensino, a pesquisa e a extensão.

As Diretrizes Curriculares Nacionais para os cursos de graduação em Educação Física (BRASIL, 2002b, 2004) estabelecem que os futuros bacharéis dessa área devem ter uma formação generalista, humanista e crítica, qualificadora da sua intervenção acadêmico-profissional, a qual, pautada na conduta ética e no rigor científico, vise a ampliação e o enriquecimento cultural das pessoas, por meio das diferentes manifestações e expressões do movimento humano (BRASIL, 2004); e que os futuros licenciados devem ter uma formação voltada à preparação para a atividade docente nas diferentes modalidades da Educação Básica, tendo como base o desenvolvimento de competências e a aquisição de conhecimentos que propiciem a inserção do individuo no debate contemporâneo mais amplo, envolvendo questões culturais, sociais e econômicas (BRASIL, 2002b).

Por sua vez, as Diretrizes para o curso de Fisioterapia apontam que a formação nesta área deve ser crítica, humanista e reflexiva, e que o egresso deve ser capaz de atuar em todos os níveis de atenção à saúde. O objeto de trabalho do fisioterapeuta é o movimento humano em todas as suas dimensões, e a responsabilidade frente à saúde não se limita ao ato técnico de 
reabilitar, mas também à busca por resolução de problemas (BRASIL, 2002a).

Tendo em vista essas Diretrizes, as Instituições de Ensino Superior são responsabilizadas pela definição de propostas pedagógicas que proporcionem uma formação inicial adequada para distintos campos de intervenção profissional. Cabe a elas estabelecer o corpo de conhecimentos a ser aprendido pelos futuros profissionais, bem como a organização e a articulação desses conhecimentos durante o período de tempo estabelecido legalmente para esse fim (NASCIMENTO et al., 2009).

Não se deve desconsiderar que os estudantes universitários trazem consigo um conjunto de saberes sobre a área que escoIheram (geralmente oriundos de vivências esportivas e/ou escolares). Contudo, a universidade e os cursos de graduação devem ser capazes de criar um ambiente no qual se possa refletir, superar, lapidar, criticar e, principalmente, ampliar esses saberes a fim de se conquistar um grau mais elaborado e sofisticado de profissionalização (VERENGUER, 2005).

Os currículos universitários deveriam, portanto, apresentar disciplinas e projetos que contemplem as questões políticas, sociais e culturais que permeiam os diversos espaços de atuação da Educação Física e da Fisioterapia, para que, ao término da graduação, os indivíduos estejam aptos a ingressar no mercado de trabalho, assumindo as responsabilidades exigidas pela profissão. Souza, Couto e Marin (2014) defendem uma formação inicial, especificamente em Educação Física, voltada para além das demandas do mercado de trabalho, a qual forme tanto um profissional consciente de sua prática, quanto um ser humano capaz de compreender a complexa sociedade e suas modificações, e que, como sujeito histórico, perceba-se como construtor dessa sociedade.

Nesta perspectiva, a forma de organizar o trabalho pedagógico encontra nas atividades de ensino, pesquisa e extensão condições favoráveis para estudar, aprofundar e construir conteúdos reconhecidos no cotidiano, na cultura, e que proporcionam o conhecimento do ambiente em que se vive e também o conhecimento da especificidade da Educação Física (DOMINGUES; KUNZ; ARAÚJO, 2011; RODRIGUES, 2014) e da Fisioterapia. Acredita-se que os projetos de ensino podem se configurar como uma pertinente alternativa para distintas possibilidades de intervenções pedagógicas, repercutindo no exercício de competências e na aquisição de saberes pelos envolvidos. Além disso, podem se constituir em ferramentas para a abordagem de questões pouco exploradas nos cursos de formação inicial em Educação Física e em Fisioterapia, mas necessárias à atuação profissional futura, como no caso das questões que envolvem o ambiente e a sociedade (MARINHO; SANTOS; FARIAS, 2012).

Partindo desses pressupostos, direciona-se a atenção à temática socioambiental. Embora a educação ambiental, com seu caráter multidisciplinar, seja apontada em documentos legais como componente do conteúdo curricular em todos os níveis de ensino (BRASIL, 1981, 1996), a efetiva inclusão da temática na educação ainda não está completamente evidente.

A educação ambiental pode ser entendida como educação política, a ser concretizada como um espaço privilegiado no constante movimento de mudança para melhores condições de vida, em estreita relação com outros campos de atuação e 
formação, potencializando a participação e o engajamento crítico e criativo dos indivíduos (MARINHO, 2004). Entende-se que ela deva ser tema transversal em cursos de formação profissional e que a universidade representa um espaço importante para a sua abordagem, tendo em vista que o que nela é feito e como ela o realiza pode servir de parâmetro para diferentes setores sociais (SORRENTINO; NASCIMENTO, 2010).

Considerando, ainda, as relações que podem ser estabelecidas entre os diferentes campos de atuação profissional da Educação Física e da Fisioterapia com o movimento humano, o ambiente e a sociedade, as quais ainda são incipientes na literatura nacional (MARINHO, 2004; MARINHO; INÁCIO, 2007; DOMINGUES; KUNZ; ARAÚJO, 2011; RODRIGUES, 2014), e a partir da identificação, em 2010, da ausência de projetos voltados ao tema no contexto desses cursos, em uma universidade pública de Santa Catarina, apresenta-se o Projeto de Ensino "Meio ambiente por inteiro: ciclo de oficinas e palestras sobre educação ambiental e qualidade de vida" (PMAPI), iniciado em 2011.

O PMAPI tem como objetivo sensibilizar a comunidade acadêmica para questões socioambientais e suas relações com a qualidade de vida, além de possibilitar o trabalho em conjunto de alunos e professores interessados, capacitando-os para auxiliar em todas as etapas de organização do projeto e permitindo o exercício de competências. Por meio de ações práticas, sua metodologia é organizada em quatro etapas para serem desenvolvidas ao longo do ano: 1) planejamento geral, com divisão dos organizadores em comissões específicas; 2) elaboração da programação do evento do projeto (ciclo de oficinas e palestras) e do plano de divulgação; 3) realização do evento; e 4) avaliações e relatório final (SANTOS et al., 2011).

Em 2013, o PMAPI foi organizado por alunos e docentes dos cursos de Licenciatura em Educação Física, Bacharelado em Educação Física e Fisioterapia; por profissionais recém-formados nesses cursos; e por alunos de pós-graduação em Educação Física e em Ciências do Movimento Humano de universidades públicas de Santa Catarina. A partir desse envolvimento foi originado este estudo, o qual objetiva apresentar as ressonâncias da participação de organizadores desse projeto, discutindo como eles se autoavaliaram; como observaram aspectos positivos e negativos do projeto; e como identificaram as contribuições dessa iniciativa para a sua formação profissional e para a mudança de hábitos e percepções referentes às questões socioambientais.

\section{MATERIAL E MÉTODOS}

Esta pesquisa é caracterizada como descritiva com abordagens quantitativa e qualitativa dos dados. Os 20 participantes do estudo integraram a comissão organizadora do PMAPI em 2013, os quais, por sua vez, ao término do projeto, foram convidados a responder um instrumento de coleta de dados elaborado especificamente para este estudo, contendo sete perguntas abertas e uma fechada referentes à autoavaliação da sua participação nessa iniciativa; à percepção do projeto como um todo; à percepção de competências; e às possíveis contribuições do projeto para a formação profissional e para a mudança de hábitos e percepções em relação às questões socioambientais.

Dentre os 20 membros da organização, 13 (12 do sexo feminino e um 
do sexo masculino), aceitaram participar voluntariamente deste estudo, respondendo ao instrumento de coleta de dados apresentado. Entre eles, dois são professores, três são alunos de graduação em Fisioterapia e um aluno de Educação Física; quatro são alunos de mestrado; e três são graduados em Educação Física.

As informações coletadas por intermédio das sete perguntas abertas foram analisadas por meio da técnica de análise de conteúdo, proposta por Bardin (2010). Realizou-se uma pré-análise (organização e leitura do material, e início da categorização); a exploração do material e tratamentos dos resultados (criação de novas categorias de análise); e a interpretação (descrição dos resultados, desvelando novas informações). Para auxiliar essa organização foi utilizado o software NVivo, versão 9.2. Os dados obtidos por meio da pergunta fechada do questionário foram analisados pela estatística descritiva, especificamente a partir da frequência simples. A organização dessas informações foi realizada com auxílio do software Microsoft Excel versão 2007.

Este estudo faz parte de um projeto de pesquisa mais amplo, aprovado pelo Comitê de Ética em Pesquisas com Seres Humanos da Universidade do Estado de Santa Catarina (parecer 317.176/2013). Todos os participantes assinaram um Termo de Consentimento Livre e Esclarecido. Com o intuito de preservar sua identidade, na descrição dos resultados foram utilizados nomes fictícios para representá-los.

\section{RESULTADOS E DISCUSSÕES}

Inicialmente, os membros da comissão organizadora foram questionados sobre os aspectos positivos do projeto. Seis destacaram a quantidade de participantes nas oficinas e palestras do evento em 2013 (mais de 600 pessoas), especialmente pelo esforço da organização em possibilitar que diferentes assuntos relacionados ao ambiente e aos cursos de formação inicial em Educação Física e em Fisioterapia fossem abordados, despertando o interesse da comunidade, mas principalmente dos acadêmicos desses cursos. Conforme descreveu um dos organizadores:

\begin{abstract}
"O que o projeto apresentou de meIhor, não apenas este ano, mas levando em consideração os anos anteriores, com toda certeza, foi a escolha das temáticas das oficinas, que nesta edição foram muito bem abordadas e de grande interesse para o público dos cursos de Educação Física e Fisioterapia, haja vista o número de inscrições que tivemos, principalmente no período da tarde, que nos anos anteriores era um período um pouco defasado" (Maria).
\end{abstract}

Também foi apontado como aspecto positivo por três participantes a integração entre os cursos, assim como outros dois destacaram a socialização entre os membros da organização. Ainda, cinco participantes ressaltaram o trabalho satisfatório da comissão organizadora, e outros três enfatizaram como positivo o alcance dos objetivos do projeto. Como pode ser percebido nas palavras de um deles:

"O número de participantes e de inscrições que tivemos este ano mostra que o projeto como um todo conseguiu atingir seus principais objetivos no sentido de possibilitar a participação discente, principalmente, fazendo com que as comissões de divulgação, avaliação, secretaria e oficinas cumprissem seu 
papel com sucesso. [...] Neste ano, por fim, destaco como ponto positivo o envolvimento da comissão organizadora nos dois dias do evento. Todos assumiram seu compromisso de auxiliar no que podiam, contribuindo muito para o sucesso do projeto" (Amélia).

Dois organizadores ainda mencionaram os novos conhecimentos possibilitados pelo projeto. Nas palavras de um deles:

\begin{abstract}
"Agregação de conhecimento nas diversas áreas, principalmente de como relacionar o meio ambiente com a fisioterapia, como na palestra de terapia assistida por cães. Além da argila medicinal que abriu novos pensamentos e técnicas para aliar as minhas futuras sessões de fisioterapia. Sem falar no grande aprendizado na parte de organizar e administrar um evento dessa grandeza" (Joana).
\end{abstract}

Outro ainda apontou a disseminação de valores relacionados ao ambiente por meio de uma ação paralela ao projeto, ocorrida antes e durante o ciclo de oficinas e palestras:

"[...] as ações de distribuição e sorteio de garrafas e canecas com as logos do evento parecem estar contribuindo para a sensibilização dos participantes e dos funcionários, professores e alunos desta universidade, no sentido de evitar a utilização e o desperdício de copos plásticos" (Amélia).

É necessário esclarecer que a ação mencionada integra um conjunto mais amplo de iniciativas de sensibilização socioambiental, desenvolvidas no contexto universitário investigado, como parte do PMAPI. Essas ações buscam fornecer informações relacionadas ao ambiente, possibilitando que os indivíduos, munidos de conhecimentos, tenham condições de tomada de decisões, de enfrentamento dos aspectos que dificultam a adoção de hábitos favoráveis ao ambiente, e de participação nas questões que envolvem a universidade. Ainda que se reconheça que ações deste teor não são suficientes para modificar concepções de problemas socioambientais, o projeto a que elas estão vinculadas parte do pressuposto de que, ainda que a passos lentos, essas ações podem ser geradoras de mudanças, agregadas a iniciativas de maior representatividade e sensibilização coletiva.

Os organizadores também foram indagados sobre os aspectos negativos do projeto. Embora dois tenham informado não perceber questões negativas, os demais participantes descreveram alguns acontecimentos pontuais durante o evento, tais como a organização de espaços e materiais de algumas oficinas, a qual poderia ser otimizada se ocorresse com mais antecedência (1); e as dificuldades encontradas para participar das atividades do evento, tendo em vista o comprometimento com a realização de tarefas relacionadas à organização (1); além de aspectos relacionados à baixa participação de professores no evento, especialmente da fisioterapia (2); e à pouca divulgação aos pós-graduandos da universidade e demais interessados (2).

Os resultados sobre a percepção de aspectos positivos e negativos do projeto evidenciam o senso crítico e o envolvimento efetivo dos seus organizadores, ao destacarem não apenas a satisfação com os temas abordados no ciclo de oficinas e palestras, os conhecimentos adquiridos, a disseminação de valores e a socialização entre os envolvidos, como também questões particulares ocorridas durante o evento que 
poderiam ser conduzidas de outra forma. É pertinente apontar que dentre os $13 \mathrm{mem}$ bros da organização participantes deste estudo, cinco integram o PMAPI desde o seu início em 2011 e quatro desde sua segunda edição em 2012, podendo ser justificado, portanto, sua sensibilidade para perceber aspectos gerais e pontuais do projeto, positivos e negativos.

Ao se destacar a aquisição de conhecimentos, apontada pelos participantes como aspecto positivo do projeto, recorre-se a Souza, Couto e Marin (2014), pois esses autores entendem que a Educação Física precisa necessariamente de conhecimentos das Ciências Naturais e das Ciências Sociais. Dessa forma, ao tratar pedagogicamente seus conteúdos de ensino há a exigência de uma visão ampliada da área, para além dos conhecimentos meramente técnicos abordados como um agrupamento de movimentos sistematizados, deslocados de qualquer contexto sociocultural. Acredita-se que esses pressupostos também se estendam a área da Fisioterapia, uma vez que seu objeto de estudo e intervenção - o movimento humano - não pode ser entendido em sua complexidade considerando-se restritamente aspectos físicos ou fisiológicos.

Freire, Verenguer e Reis (2002) salientam que, na universidade, é preciso que o acesso ao conhecimento ocorra na mesma velocidade que na sociedade em geral. Para isso, faz-se necessário repensar as formas tradicionais de ensino nas quais os alunos desempenham um papel eminentemente passivo, como nas aulas expositivas em que o docente é o único responsável pela apresentação do conhecimento. Os graduandos precisam participar do processo de produção de conhecimentos, valorizar sua busca, participando ativamente do seu processo de profissionalização.

Nessa perspectiva, no presente estudo, os participantes também foram questionados sobre os aspectos que mais contribuíram no projeto. Dois apontaram sua contribuição com a comissão de avaliação; três informaram contribuir com a divulgação do evento; cinco com o planejamento e organização prévia desse evento; quatro com o planejamento e realização das oficinas. Cinco consideraram que contribuíram mais durante a realização do evento, e outros cinco nas atividades da secretaria (inscrições e certificados). Dois organizadores informaram que contribuíram em todos os aspectos do projeto.

Em contrapartida, sobre o que menos contribuíram, os participantes apontaram alguns períodos em que não puderam comparecer ao evento por motivos de compromissos pessoais, dificuldades de transporte, problemas familiares e de saúde. Além disso, dois informaram contribuir pouco com o planejamento do evento em virtude de compromissos de estudo e por terem se envolvido tardiamente com o projeto. Dois ressaltaram que poderiam ter contribuído mais com a divulgação e três informaram que se envolveram pouco com atividades de outras comissões por terem que cumprir as tarefas de sua própria comissão. Um organizador considerou que não deixou de contribuir em nenhum aspecto porque cumpriu tudo o que the foi solicitado.

Nota-se que os participantes perceberam não apenas o que mais contribuíram, mas também o que pouco colaboraram no projeto. A cada ano são formadas comissões de organização específicas (secretaria, divulgação, oficinas e avaliação), a fim de 
otimizar a organização geral, fazendo com que cada um se comprometa com funções específicas, porém necessárias ao projeto como um todo. Embora sejam estimulados a também colaborar com todas as comissões, talvez por esta organização os participantes tenham observado contribuir mais com tarefas relacionadas à sua comissão e menos com algumas tarefas pontuais em virtude de outros compromissos.

Após terem refletido sobre suas contribuições ao PMAPI, solicitou-se que os organizadores citassem três palavras para traduzir sua participação no projeto. As palavras descritas foram: comprometimento (4); organização (4); dedicação (3); integração (2); iniciativa (2); alegria (2); satisfação (2); confiança (1); responsabilidade (1); interdisciplinaridade (1); solicitude (1); cansaço (1); interesse (1); aprendizado (1); seriedade (1); paixão (1); assiduidade (1); compromisso (1); empenho (1); disposição (1); esforço (1); cooperação (1); e determinação (1).

É possível destacar que a socialização foi frequentemente mencionada pelos organizadores, sendo incluída não apenas entre os aspectos positivos do projeto, como também por meio das palavras "integração" e "cooperação" para traduzir a participação nessa iniciativa. A socialização acadêmica na formação inicial deve ser enfatiza nas disciplinas e nos projetos que compõem o currículo. As relações estabelecidas durante esse período favorecem o encorajamento para assumir os desafios da profissão, a construção da identidade profissional e a aquisição de conhecimentos no desenvolvimento da carreira, que se estruturam como um conjunto de fatores relevantes na socialização profissional. Assim, a integração entre acadêmicos de diferentes cursos deve ser vista como preponderante e benéfica, a fim de que em um contexto futuro de intervenção, ações conjuntas sejam desenvolvidas em prol do bem estar do ser humano (FARIAS, 2010; MARINHO; SANTOS; FARIAS, 2012).

Para além da ênfase na socialização, várias palavras com sentido positivo e que expressam satisfação foram citadas para designar a participação dos membros da organização no PMAPI. Nessa perspectiva, e independentemente das contribuições em determinadas comissões e atividades do projeto, deve-se salientar a possibilidade de participação efetiva que essa iniciativa proporcionou aos seus organizadores. $\mathrm{Na}$ visão de Sorrentino (2000), participar, no contexto da educação ambiental, significa oferecer condições básicas de infraestrutura e de acesso a todos; disponibilizar informações e permitir que as pessoas dialoguem, troquem ideias, sentimentos e afetividades. Significa, também, possibilitar que todos tenham vez e voz na tomada de decisões; que se comprometam de corpo e alma com a situação ambiental; e, ainda, que se sintam pertencentes ao local, ao planeta e à humanidade, percebendo que tudo isso lhes diz respeito. Acredita-se que seja nessa direção que devam caminhar os fazeres educacionais atrelados ao ambiente e a sociedade, neste caso, especificamente quando direcionados à formação inicial em Educação Física e em Fisioterapia.

A partir do envolvimento dos participantes, eles foram interrogados sobre as contribuições do projeto para a sua formação profissional em Educação Física ou em Fisioterapia. A maioria (9) apontou a contribuição do PMAPI para aprender mais sobre o tema ambiente, além de visualizar possibilidades de aplicar esses conhecimentos 
em seu contexto de atuação profissional (2), em desenvolvimento ou futuro. Conforme foi descrito por duas organizadoras:

"O meio ambiente está presente em cada detalhe, e como fisioterapeuta vem a ser um aliado no tratamento dos futuros pacientes" (Luiza).

"No conhecimento teórico e prático a respeito da possibilidade de utilização de recursos alternativos para práticas corporais na escola ou com outra população, que eu nem imaginava ser possível (como surfar em uma prancha de garrafas pet) sendo que tais recursos contribuem para a preservação do meio ambiente e estimulam a nossa capacidade de criatividade" (Maria).

Quatro membros da organização apontaram que o projeto contribuiu para aprenderem a organizar um evento, além de possibilitar o trabalho em equipe, o contato com o público, a resolução de problemas e a distribuição de tarefas. Nas palavras de uma delas:

"O projeto é uma boa oportunidade para se aprender a trabalhar melhor em grupo, a distribuir funções, mas também uma boa oportunidade para desenvolver a capacidade de organização e planejamento. Além disso, as palestras voltadas para a fisioterapia foram importantes para descobrir possibilidades de interação entre a fisioterapia e o ambiente" (Mariana).

Dois integrantes consideraram que o projeto contribuiu para sua formação profissional e pessoal. Como pode ser observado nas palavras de uma organizadora:

"A cada ano aprendo mais sobre as questões socioambientais e isso está contribuindo não apenas para a minha formação profissional, no sentido de perceber as possibilidades de inter-relação entre Educação Física e ambiente, mas, principalmente, para a minha formação pessoal. A sensibilização que este projeto promove nas pessoas faz com que repensemos atitudes, comportamentos, e o nosso próprio modo de viver. Cada vez mais tenho vontade de ser uma pessoa melhor, mais cooperativa e afetiva" (Amélia).

Dessa forma, na visão dos participantes, o envolvimento com o PMAPI contribui efetivamente para a sua formação profissional. Assim como Marinho (2004), considera-se que os conteúdos dos cursos de formação inicial, no presente caso em Educação Física e em Fisioterapia, dentre os quais as questões socioambientais possam ser inseridas, sejam repensados e reformulados, privilegiando essa nova demanda. A temática socioambiental implica em diferentes espaços de atuação para os profissionais dessas áreas, exigindo uma nova postura, capaz de corresponder, qualitativamente, ao interesse dos envolvidos, dando vigor à potencialidade do assunto.

Nessa direção, acredita-se que os cursos de formação inicial em Educação Física e em Fisioterapia possam se valer de iniciativas como o PMAPI para formar profissionais sensibilizados para incluir em sua futura atuação novas possibilidades de experiências para seus alunos, clientes e pacientes, atreladas às questões socioambientais, multiplicando-se, assim, a adaptação de profissionais e estudantes a uma diferente realidade dessas áreas.

Nesses apontamentos, registra-se não apenas a necessidade de inclusão das questões socioambientais nos cursos de formação inicial, mas de que haja um projeto 
interdisciplinar, com a indispensável inclusão de saberes tradicionais, ampliando e enriquecendo a formação de novos cidadãos na direção de um compromisso ético com a profissão. Importa ressaltar que o conhecimento é um dos aspectos que diferencia (de alguma forma) os seres humanos de outros seres. É ele que pode, ou não, remeter as pessoas a um comportamento ético, pois conhecimento é poder e a utilização desse poder requer também engajamento. Além dos conhecimentos acadêmicos, há de se produzir, nos cursos de graduação, um outro saber, partilhado, solidário, transformador, o qual pode ser oportunizado por meio de um processo educativo atrelado às questões ambientais (MARINHO; INÁCIO, 2007; RODRIGUES, 2014).

Nesse sentido, também foi perguntado se os organizadores consideram que a sua participação no projeto está contribuindo para a mudança de hábitos e percepções sobre as questões socioambientais. Dez enfatizaram a mudança efetiva de hábitos após o envolvimento com o projeto, exemplificando a separação dos resíduos e o evitar desperdícios de todos os tipos (energia, papel, etc.). Sete participantes apontaram a mudança de percepções socioambientais, especialmente no sentido de refletir sobre o tema nas atividades diárias.

Diante desses resultados, recorre-se a Sauvé (2005), haja vista que essa autora aponta que a mudança de valores e de atitudes mais favoráveis ao ambiente pode ser induzida por meio de iniciativas voltadas à educação ambiental, as quais tendo início em uma comunidade local, podem, posteriormente, disseminar-se por redes mais amplas de solidariedade. Ao conhecer o valor do ambiente e ao se sentir parte dele, os indivíduos são incitados a refletir sobre soluções para os problemas existentes e a agir para tentar minimizá-los.

No contexto universitário, Verenguer (2005) enfatiza que, antes de se constituir em um espaço que outorga diplomas, as instituições de ensino superior são um lócus no qual a reflexão da realidade, a proposição de alternativas e a responsabilidade com a mudança estão incluídas como eixos norteadores de qualquer curso de graduação. Todas as atividades que integram um curso de formação inicial, sejam elas de ensino, pesquisa e/ou extensão, devem proporcionar a aquisição de novos saberes, visando, entre outras possibilidades, a realidade na qual o indivíduo está inserido. Isso significa que como profissional-cidadão o indivíduo deve atuar como agente de mudança.

A partir desse reconhecimento, constata-se a importância de introduzir propostas educacionais que possibilitem o estabelecimento e a valorização de uma cultura efetiva, estimulando novos estudos e intervindo de maneira holística, relacional e integrativa. Além disso, a mudança de hábitos e a troca de informações e conhecimentos adquiridos com outros grupos de pessoas, como amigos e colegas de trabaIho, em diversos contextos, podem agregar competências almejadas para a formação profissional (MARINHO; SANTOS; FARIAS, 2012). Nessa direção, os integrantes da comissão organizadora foram indagados, por fim, sobre a frequência de manifestação de algumas competências durante o projeto, conforme pode ser observado na Tabela 1. 
Tabela 1 - Percepção de competências pelos membros da organização do projeto.

\begin{tabular}{lccc}
\hline \multirow{2}{*}{ Competências } & \multicolumn{3}{c}{ Frequência } \\
\cline { 2 - 4 } & Todas às vezes & Muitas vezes & Poucas vezes \\
\hline Capacidade de relacionamento & 7 & 6 & 0 \\
\hline Liderança & 7 & 4 & 2 \\
\hline Flexibilidade & 7 & 4 & 2 \\
\hline Criatividade & 5 & 4 & 4 \\
\hline Persistência & 6 & 5 & 2 \\
\hline Iniciativa & 7 & 5 & 1 \\
\hline
\end{tabular}

Fonte: Autoria própria (2015).

Nota-se que os participantes perceberam frequentemente a manifestação de competências durante seu envolvimento com o PMAPI. Talvez a organização dos indivíduos em diferentes comissões de atividades, bem como as particularidades dos campos de intervenção da Educação Física e de Fisioterapia, tenham possibilitado o exercício de competências diversas.

Embora esse projeto de ensino tenha originado o presente estudo e se mostrado significativo para a percepção de competências nas áreas da Educação Física e da Fisioterapia, seria ingênuo acreditar que ele, por si só, daria conta de suprir todas as demandas e carências dos futuros profissionais, especificamente em relação às questões socioambientais. As competências percebidas nessa iniciativa não se reproduzirão necessariamente em um contexto futuro de intervenção.

"Saber sobre" e "saber fazer" não garantem uma atuação profissional eficiente. É necessário, antes de tudo, um "saber ser", apresentando atitudes e valores que caracterizem uma ação ética (FREIRE; VERENGUER; REIS, 2002). A manifestação de competências se modifica conforme a época, os interesses e as pessoas. Dessa forma, pode-se dizer que a competência não é estática, e sim, construída ao longo da vida e das experiências pessoais e profissionais (RIBAS, 2000). Portanto, assim como Nascimento (2002), ratifica-se um entendimento mais amplo de formação inicial, aqui em Educação Física e em Fisioterapia, percebendo-a como o período no qual os estudantes podem ter contato com as competências nucleares de sua profissão, as quais por sua vez, podem se manifestar por meio de projetos de ensino.

\section{CONCLUSÕES}

Diante do exposto, percebe-se a necessidade de oportunizar a acadêmicos e professores a aquisição de conhecimentos relacionados direta ou indiretamente à formação e atuação profissional em Educação Física e em Fisioterapia. No entanto, a abordagem da temática socioambiental por meio de disciplinas curriculares dos cursos da instituição investigada parece 
ainda ser insuficiente para que tal propósito seja atingido. Assim, projetos de ensino como o ora apresentado podem se tornar opções relevantes para novas intervenções pedagógicas, multiplicando ideias e ideais, disseminando possibilidades de um ambiente ser melhor conhecido, vivido e defendido por acadêmicos e professores de cursos de Educação Física e de Fisioterapia.

Embora sejam reconhecidas as limitações deste estudo, especialmente no sentido de projetar reflexões sobre a formação profissional nas áreas do conhecimento em questão, a partir de um projeto de ensino específico e de abrangência regional, espera-se que esse trabalho contribua com o avanço das investigações sobre a inter-relação dos temas ambiente e formação profissional, estabelecendo interfaces com a Educação Física e a Fisioterapia, despertando novos interesses e possibilidades de atuação profissional nesses contextos. Sugere-se a realização de novas pesquisas sobre o assunto, a fim de identificar novas possibilidades de inserção na formação e as contribuições das questões socioambientais para a intervenção em Educação Física e Fisioterapia.

\section{REFERÊNCIAS}

BARDIN, L. Análise de conteúdo. Ed. rev. e atual. Lisboa: Edições 70, 2010.

BISPO JÚNIOR, J. P. Formação em fisioterapia no Brasil: reflexões sobre a expansão do ensino e os modelos de formação. História, Ciências, Saúde Manguinhos, Rio de Janeiro, v. 16, n. 3, p. 655-668, jul./set., 2009.

BRASIL. Ministério da Educação. Conselho Nacional de Educação. Câmara de
Educação Superior. Resolução No 7, de 31 de março de 2004: institui as Diretrizes Curriculares Nacionais para os cursos de graduação em Educação Física, em nível superior de graduação plena. Brasília, 2004.

- Ministério da Educação. Conselho Nacional de Educação. Câmara de Educação Superior. Resolução CNE/CES 4, de 19 de fevereiro de 2002: institui Diretrizes Curriculares Nacionais do Curso de Graduação em Fisioterapia. Brasília, 2002.

. Ministério da Educação. Conselho Nacional de Educação. Conselho Pleno. Resolução CNE/CP No 1, de 18 de fevereiro de 2002: institui Diretrizes Curriculares Nacionais para a Formação de Professores da Educação Básica, em nível superior, curso de licenciatura, de graduação plena. Brasília, 2002.

. Ministério da Educação. Conselho Nacional de Educação. Lei n. 9.394, de 20 de dezembro de 1996: institui as Diretrizes e Bases da Educação Nacional. Brasília, 1996.

. Ministério do Meio Ambiente. Lei n. 6.938, de 31 de agosto de 1981: dispõe sobre a Política Nacional do Meio Ambiente, seus fins e mecanismos de formulação e aplicação, e dá outras providências. Brasília, 1981.

DOMINGUES, S. C.; KUNZ, E.; ARAÚJO, L. C. G. Educação ambiental e educação física: possibilidades para formação de professores. Revista Brasileira de Ciências do Esporte, Campinas, v. 33, n. 3, p. 559-571, jul. /set., 2011.

FARIAS, G. O. Carreira docente em Educação Física: uma abordagem na construção da trajetória profissional do professor. 2010. 303 f. Tese (Doutorado 
em Educação Física) - Centro de Desportos, Programa de Pós-graduação em Educação Física, Universidade Federal de Santa Catarina, Florianópolis, 2010.

FREIRE, E. S.; VERENGUER, R. C. G.; REIS, M. C. C. Educação Física: pensando a profissão e a preparação profissional. Revista Mackenzie de Educação Física e Esporte, São Paulo, ano 1, n. 1, p. 39-46, 2002.

MARINHO, A. Atividades na natureza, lazer e educação ambiental: refletindo sobre algumas possibilidades. Motrivivência, Florianópolis, ano XVI, n. 22, p. 47-69, jun., 2004.

MARINHO, A.; INÁCIO, H. L. D. Educação física, meio ambiente e aventura: um percurso por vias instigantes. Revista Brasileira de Ciências do Esporte, Campinas, v. 28, n. 3, p. 55-70, maio, 2007.

MARINHO, A.; SANTOS, P. M.; FARIAS, G. O. Competências e formação profissional: reflexões sobre um projeto de ensino. Revista Brasileira de Ciência e Movimento, Brasília, v. 20, n. 3, p. 46-54, dez., 2012.

MARQUES, F. B; FIGUEIREDO; Z. C. C. Diretrizes Curriculares Nacionais e suas repercussões nos currículos de formação docente em Educação Física. Motrivivência, Florianópolis, v. 26, n. 43, p. 30-43, dez., 2014.

MEYER, P. F.; COSTA, Í. C. C.; GICO, V. V. Ciências sociais e fisioterapia: uma aproximação possível. História, Ciências, Saúde-Manguinhos, Rio de Janeiro, v. 13 , n. 4 , p. 877-890, out./ dez., 2006.

NASCIMENTO, J. V. Formação profissional em Educação Física: contextos de desenvolvimento curricular. Monte Claros: Unimontes, 2002.

NASCIMENTO, J. V.; RAMOS, V.; MARCON, D.; SAAD, M. A.; COLLET, C. Formação acadêmica e intervenção pedagógica nos esportes. Motriz, Rio Claro, v. 15, n. 2, p. 358366, abr./jun., 2009.

REBELATtO， J. R.; BOtOMÉ, S. $P$. Fisioterapia no Brasil: fundamentos para uma ação preventiva e perspectivas profissionais. 2. ed. São Paulo: Manole, 1999.

RIBAS, M. H. Construindo a competência: processo de formação de professores. São Paulo: Olho d'Água, 2000.

RODRIGUES, C. A pesquisa acadêmica sobre a inserção da dimensão ambiental na Educação Física no Brasil. Motrivivência, Florianópolis, v. 26, n. 42, p. 194-206, jun., 2014.

SANTOS, P. M.; ASATO, M. H.; LIMA, L. D.; LABORNE, I. B.; AMARAL, L. C.; MARINHO, A. Meio ambiente por inteiro: apresentando um projeto de ensino. In: CONGRESSO BRASILEIRO DE CIÊNCIAS DO ESPORTE, 17., 2011, Porto Alegre (RS). Anais... Porto Alegre, 2011. p. 1-8.

SAUVÉ, L. Educação ambiental: possibilidades e limitações. Educação e Pesquisa, São Paulo, v. 31, n. 2, p. 317-322, maio/ago., 2005.

SORRENTINO, M. Crise ambiental e educação. In: QUINTAS, J. S. Pensando e praticando a educação ambiental na gestão do meio ambiente. Brasília: IBAMA, 2000. p. 93-114.

SORRENTINO, M.; NASCIMENTO, E. P. Universidade e políticas públicas de educação ambiental. Educação em Foco, Juíz de Fora, v. 14, n. 2, p. 15-38, set., 2009/fev., 2010. 
SOUZA, M. S.; COUTO, M. L.; MARIN, E. C. A relação entre as Ciências Sociais e as Ciências Naturais na formação em Educação Física do CEFD/UFSM. Pensar a Prática, Goiânia, v. 17, n. 1, p. 01294, jan./mar., 2014.

SOUZA, M. S.; FUCHS, M. M.; RAMOS; F. K. Diretrizes Curriculares Nacionais e o processo de formação de professores em Educação Física: análise a partir da legalidade, conhecimento e mundo/ mercado de trabalho. Motrivivência, Florianópolis, v. 26, n. 43, p. 17-29, dez., 2014.

VERENGUER, R. C. G. Mercado de trabalho em Educação Física: reestruturação produtiva, relações de trabalho e intervenção profissional. Revista Mackenzie de Educação Física e Esporte, São Paulo, ano 4, n. 4, p. 3954, 2005.

\title{
VOCATIONAL TRAINING IN PHYSICAL THERAPY AND PHYSICAL EDUCATION: resonance about of draft environmental issues in education
}

\begin{abstract}
This study presents resonances of the participation from an organizing committee of a school project on environmental issues, developed in a public university of Santa Catarina, in context of courses in Physical Education and Physiotherapy. This is a descriptive research with quantitative and qualitative approaches. At the end of this project, 13 participants answered a questionnaire mixed up. The data were analyzed using a descriptive statistics and content analysis. The results indicate, among other issues, that the participants felt contributions of the project to learn more about the environment issue and to envision new possibilities for their professional performance. In addition, they've noticed the manifestation of skills.
\end{abstract}

Keywords: Teaching; Environment; Physical Education and Training; Physical Therapy Specialty

\section{LA FORMACIÓN PROFESIONAL EN EDUCACIÓN FÍSICA Y FISIOTERAPIA: resultados de un proyecto de enseñanza sobre cuestiones socioambientales}

\section{RESUMEN}

Este estudio presenta los resultados de la participación del comité organizador de un proyecto de enseñanza sobre cuestiones socioambientales, desarrollado en una universidad pública de la provincia de Santa Catarina, en el contexto de los cursos de Educación Física y Fisioterapia. Es una investigación descriptiva con los enfoques cuantitativos y cualitativos. Al final del proyecto, 13 participantes contestaron a un cuestionario mixto. Los datos fueron analizados utilizando estadística descriptiva y 
análisis de contenido. Los resultados indican que, entre otras cuestiones, los participantes perciben contribuciones del proyecto para aprender más sobre el tema del medio ambiente y para imaginar nuevas posibilidades de acción profesional. Además, ellos perciben a menudo la manifestación de competencias.

Palabras clave: Enseñanza; Medio Ambiente; Educación Física; Fisioterapia

Recebido em: março/2015 Aprovado em: novembro/2015 